\title{
Use of Simple Clinical Predictors on Preoperative Diagnosis of Difficult Endotracheal Intubation in Obese Patients
}

\author{
Edno Magalhães* ${ }^{1}$, Felipe Oliveira Marques ${ }^{2}$, Cátia Sousa Govêia ${ }^{3}$, \\ Luis Cláudio Araújo Ladeira ${ }^{4}$, Jader Lagares ${ }^{5}$
}

1. Responsible for CET /SBA, Anesthesiology Center, Universidade de Brasília

2. ME3, CET/SBA, Anesthesiology Center, Universidade de Brasília

3. Co-responsible for CET/SBA, Anesthesiology Center, Universidade de Brasilia

4. Co-responsible for CET/SBA, Anesthesiology Center, Universidade de Brasília

5. ME1, CET/SBA, Anesthesiology Center, Universidade de Brasilia

Received from Universidade de Brasilia, School of Medicine (CET/SBA), Anesthesiology

Center at Universidade de Brasília, Brasília, DF, Brazil.

Submitted on January 26, 2012. Approved on May 7, 2012.

\author{
KEYWORDS: \\ Intubation, \\ Intratracheal; \\ Obesity; \\ Sleep apnea, \\ Obstructive; \\ Risk Assessment.
}

\begin{abstract}
Background and objectives: Although the incidence of difficult laryngoscopy is similar in obese and non-obese patients, there are more reports of difficult intubation in obese individuals. Alternatives for the diagnosis and prediction of difficult intubation in the preoperative period may help reduce anesthetic complications in obese patients. The aim of this study was to identify predictors for the diagnosis of difficult airway in obese patients, correlating with the clinical methods of pre-anesthetic evaluation and polysomnography. We also compared the incidence of difficult facemask ventilation and difficult laryngoscopy between obese and non-obese patients, identifying the most prevalent predictors.

Methods: Observational, prospective and comparative study, with 88 adult patients undergoing general anesthesia. In the preoperative period, we evaluated a questionnaire on the clinical predictors of the obstructive sleep apnea syndrome (OSAS) and anatomical parameters. During anesthesia, we evaluated difficult facemask ventilation and laryngoscopy. Descriptive statistics and correlation test were used for analysis.

Results: Patients were allocated into two groups: obese group $(n=43)$ and non-obese group $(n=$ 45). Physical status, prevalence of snoring, hypertension, diabetes mellitus, neck circumference, and Mallampati index were higher in the obese group. Obese patients had a higher incidence of difficult facemask ventilation and laryngoscopy. There was no correlation between anatomical or clinical variable and difficult facemask ventilation in both groups. In obese patients, the diagnosis of OSAS showed strong correlation with difficult laryngoscopy.

Conclusions: The clinical and polysomnographic diagnosis of OSA proved useful in the preoperative diagnosis of difficult laryngoscopy. Obese patients are more prone to difficult facemask ventilation and laryngoscopy.

๑ 2013 Sociedade Brasileira de Anestesiologia. Published by Elsevier Editora Ltda. All rights reserved.
\end{abstract}

*Corresponding author: Universidade de Brasília, Hospital Universitário de Brasília, Centro de Anestesiologia, SQS 113 C 406, CEP 70376030, Brasília, DF, Brasil.

E-mail: ednomag@gmail.com

ISSN/\$ - see front metter @ 2013 Sociedade Brasileira de Anestesiologia. Published by Elsevier Editora Ltda. All rights reserved. 


\section{Introduction}

Obesity may be defined as excess of fat in the body. A person is considered obese when excess fat affects his/her physical and mental health and decreases his/her life expectancy ${ }^{1}$. The World Health Organization (WHO) defines an obese person as one who has a body mass index $(\mathrm{BMI})$ greater than 30 $\mathrm{kg}$ per square meter of body surface $\left(B M I \geq 30 \mathrm{~kg} \cdot \mathrm{m}^{-2}\right)$.

The incidence of obesity has increased considerably almost worldwide. In Brazil, the prevalence rate is $13.3 \%$ for the female and $7 \%$ for the male population. In Europe and the U.S., the prevalence rates are 20 and $22.5 \%$, respectively. The ascent rate varies from $0.5 \%$ to $1 \%$ per year in developed countries. Only Japan and the Netherlands have stable rates ${ }^{2}$.

Improper airway management is the most frequent cause of complications related to anesthesiology and accounts for $30 \%$ of deaths, with anesthesia as the primary cause. In the last century, it became clear the importance of airway prior assessment as a means to decrease complications in anesthesia. Several devices and techniques were developed and, a few decades ago, Cormack and Lehane, and Mallampati et al. developed tables for predicting difficult intubation.

Within this context, it is important to distinguish difficult laryngoscopy from difficult tracheal intubation. Difficult laryngoscopy is an objective parameter related to the classification of larynx visualization in grades III or IV according to Cormack and Lehane. The concept of difficult intubation, a more subjective evaluation, is related to the physician's experience and the number of attempts or techniques used during the procedure. One patient with grade III or IV in the classification of Cormack and Lehane may undergo intubation without difficulty. On the other hand, one patient with Cormack's grade I may have limited access to the airways due to a subglottic tumor or tracheal deviation.

In obese individuals, the incidence of difficult laryngoscopy is similar to that of non-obese individuals (about $10 \%)^{6}$. Nevertheless, there are more reports on difficult intubation in obese patients. This is believed to be due to changes in upper airway, present in patients with BMI above $30 \mathrm{~kg} \cdot \mathrm{m}^{-23,4}$. Some clinical predictors are related to increased risk of difficult airway in obese patients. Mallampati's grade III or IV, large neck circumference, and previous diagnosis of obstructive sleep apnea syndrome (OSAS) are factors related to difficult intubation in obese patients ${ }^{3}$.

OSAS is a clinical condition associated with obesity and difficult intubation. It results from partial or complete airway obstruction during sleep, and its prevalence varies between $9 \%$ and $24 \%$ in the general population ${ }^{5}$. Non-treated OSAS may lead to cognitive dysfunction, decreased job performance, and poor quality of life. The main symptoms are associated with loud snoring, pauses in breathing during sleep, and daytime sleepiness ${ }^{6}$. Prevalence is higher in specific subgroups, such as obese and overweight patients and older individuals. Risk factors are smoking, alcoholism, male gender, and family history of OSAS.

Because it is a clinical condition with significant relevance to the anesthetic procedure, recent consensus of the American Society of Anesthesiologists (ASA) emphasize the need to diagnose OSAS patients in the perioperative period through clinical history, physical examination, and laboratory tests ${ }^{7}$. Various strategies have been proposed to improve the diagnosis and treatment of obstructive sleep apnea. Prediction algorithms and the use of home monitoring at night, such as oximetry, have improved the access to diagnostic tests ${ }^{5}$. In centers having no polysomnography as preoperative routine, the investigation of some specific clinical indicators may help identify patients with a possible diagnosis of OSAS ${ }^{5}$.

The development of alternative ways of diagnosing obstructive sleep apnea and foreseeing difficult tracheal intubation in the preoperative period may help reduce the rates of anesthetic complications in obese patients. The objectives are to identify independent clinical predictors to predict and diagnose difficult airway in obese patients during the preoperative period, through the correlation between clinical methods of preanesthetic evaluation and polysomnography results. The secondary objective is to compare the incidence of difficult facemask ventilation and laryngoscopy between obese and non-obese patients and assess the most prevalent predictors in each group.

\section{Method}

This is an observational, prospective, and comparative study. After approval by the Human Research Ethics Committees (CEP) of the Universidade de Brasília, each patient gave previous informed consent.

The sample consisted of patients from the University Hospital of Brasília aged over 18 years undergoing general anesthesia for surgical procedures from May to November 2011. In the preoperative period, all patients completed a questionnaire of clinical predictors for preoperative diagnosis of OSAS ${ }^{7}$.

Sample size was determined based on the estimated mean incidence of difficult laryngoscopy in the population, with calculated minimum sample of 40 patients in each group.

Patients were allocated into two groups. The first group consisted of patients diagnosed with obesity according to WHO criteria (BMI $\geq 30 \mathrm{~kg} \cdot \mathrm{m}^{-2}$ ) and the second group included patients with $\mathrm{BMI}<30 \mathrm{~kg} \cdot \mathrm{m}^{-2}$.

Demographic variables evaluated were age, sex, height, weight, BMI, and ASA physical status. Clinical predictors of OSAS were self-reported snoring or family history of snoring, treated or untreated systemic arterial hypertension $(\mathrm{AH})$, type 2 diabetes mellitus (DM), daytime sleepiness and apnea during sleep. The anatomical parameters assessment was based on the modified Mallampati index, measurement of neck circumference, thyromental and sternomental distances, mouth opening, mandibular protrusion capacity, mobility, and cervical morphology.

We investigated the existence of preoperative polysomnography examination on medical records. Clinical data were correlated with the results of polysomnographic studies to identify the variables related to OSAS diagnosis.

We evaluated the experience of the anesthesiologist who performed the anesthetic procedure, difficult facemask ventilation, and Cormack-Lehane classification during laryngoscopy. Difficult laryngoscopy was considered as grade III or IV, according to Cormack-Lehane classification system.

For statistical analysis, we used Excel (C) (Microsoft Corporation) software for descriptive statistics and correlation analysis. For comparison between obese and non-obese 
patients, continuous data were analyzed using Student's t-test and unpaired nominal variables using the chi-square test. A value of $p<0.05$ was considered significant.

\section{Results}

The sample consisted of 83 patients allocated into two groups: obese group $(n=43)$ and non-obese group $(n=45)$. Only nine patients in the obese group and one patient in the non-obese group had preoperative polysomnography results in their records.

There was no difference between both groups regarding age, sex, and height. Weight, BMI, and ASA physical status were significantly higher in the obese group (Table 1).

The higher prevalence of snoring, hypertension, and type 2 diabetes mellitus in obese patients was statistically significant $(p<0.05)$. There was no difference between groups regarding daytime sleepiness and apnea during sleep (Table 2).

The values for neck circumference and Mallampati modified index were significantly higher in obese patients $(p<$ 0.05 ). There was no difference between groups regarding thyromental and sternomental distances, mouth opening, mandibular morphology, mobility capacity, and cervical protrusion (Table 3).

There was no statistically significant difference between groups regarding the experience of physicians performing the airway access (Table 4). The differences in difficult facemask

Table 1 Demographic Data.

\begin{tabular}{llll}
\hline & Obese & Non-obese & \\
\hline $\mathrm{n}$ & 43 & 45 & \\
Parameters & Mean $( \pm \mathrm{SD})$ & Mean $( \pm \mathrm{SD})$ & $\mathrm{P}$ \\
\hline Age (years) & $48.8( \pm 13.2)$ & $49.6( \pm 13.7)$ & 0.80 \\
Sex & $33 \mathrm{~F} / 10 \mathrm{M}$ & $36 \mathrm{~F} / 9 \mathrm{M}$ & 0.19 \\
Height $(\mathrm{cm})$ & $160.3( \pm 9.7)$ & $160.1( \pm 8.1)$ & 0.94 \\
Weight $(\mathrm{kg})$ & $94.6( \pm 20.6)$ & $63.4( \pm 9.2)$ & $<0.001^{*}$ \\
BMI $\left(\mathrm{kg} . \mathrm{m}^{-2}\right)$ & $36.7( \pm 6.1)$ & $24.7( \pm 3.1)$ & $<0.001^{*}$ \\
Physical status & $35 \mathrm{I}-\mathrm{II} / 8 \mathrm{III}-\mathrm{IV}$ & $45 \mathrm{I}-\mathrm{II} / 0 \mathrm{III}-\mathrm{IV}$ & $<0.05^{*}$ \\
\hline
\end{tabular}

BMI: Body Mass Index.

Table 2 Prevalence of the Clinical Predictors of OSAS.

\begin{tabular}{llll}
\hline Predictors & $\begin{array}{l}\text { Obese } \\
\mathbf{n}\end{array}$ & $\begin{array}{l}\text { Non-obese } \\
\mathrm{p}\end{array}$ & 45 \\
\hline Snoring & $86.0 \%$ & $35.6 \%$ & $<0.05^{*}$ \\
Apnea & $13.0 \%$ & $6.7 \%$ & $>0.05$ \\
Sleepiness & $41.9 \%$ & $24.4 \%$ & $>0.05$ \\
AH & $48.8 \%$ & $26.7 \%$ & $<0.05^{*}$ \\
Type-2 DM & $32.6 \%$ & $0 \%$ & $<0.05^{*}$ \\
\hline
\end{tabular}

AH: Arterial Hypertension; DM: Diabetes Mellitus
Table 3 Anatomical Evaluation.

\begin{tabular}{|c|c|c|c|}
\hline Parameters & $\begin{array}{l}\text { Obese } \\
\text { Mean }( \pm S D)\end{array}$ & $\begin{array}{l}\text { Non-obese } \\
\text { Mean }( \pm S D)\end{array}$ & $\mathrm{p}$ \\
\hline $\begin{array}{l}\text { Neck } \\
\text { circumference } \\
\text { (cm) }\end{array}$ & $40.7( \pm 3.4)$ & $36.4( \pm 4.0)$ & $<0.001^{*}$ \\
\hline $\begin{array}{l}\text { Thyromental } \\
\text { distance }(\mathrm{cm})\end{array}$ & $8.1( \pm 1.4)$ & $7.6( \pm 1.0)$ & 0.07 \\
\hline $\begin{array}{l}\text { Sternomental } \\
\text { distance }(\mathrm{cm})\end{array}$ & $15.1( \pm 1.8)$ & $14.4( \pm 1.6)$ & 0.07 \\
\hline $\begin{array}{l}\text { Mouth opening } \\
(\mathrm{cm})\end{array}$ & $4.6( \pm 0.7)$ & $4.5( \pm 0.6)$ & 0.48 \\
\hline $\begin{array}{l}\text { Mallampati } \\
\text { classification }\end{array}$ & $\begin{array}{l}35 \text { I-II/ } 6 \\
\text { III-IV }\end{array}$ & 44 I-II/ 1 III-IV & $<0.05^{*}$ \\
\hline $\begin{array}{l}\text { Adequate } \\
\text { mandibular } \\
\text { protrusion (\%) }\end{array}$ & 86.0 & 90.1 & $>0.05$ \\
\hline $\begin{array}{l}\text { Adequate } \\
\text { cervical } \\
\text { mobility (\%) }\end{array}$ & 90.7 & 95.6 & $>0.05$ \\
\hline $\begin{array}{l}\text { Normal } \\
\text { mandibular } \\
\text { morphology (\%) }\end{array}$ & 93.0 & 95.6 & $>0.05$ \\
\hline
\end{tabular}

Table 4 Anesthesiologist's Experience.

\begin{tabular}{llll}
\hline & Obese & Non-obese & $\mathrm{p}$ \\
\hline 1 year & 39 & 34 & $>0.05$ \\
$>1$ year & 4 & 11 & $>0.05$ \\
\hline
\end{tabular}

Table 5 Airway Access.

\begin{tabular}{llll}
\hline Parameters & Obese & Non-obese & $\mathrm{p}$ \\
\hline Difficult ventilation & $16.3 \%$ & $0 \%$ & $<0.05^{*}$ \\
Difficult laryngoscopy & $9.3 \%$ & $0 \%$ & $<0.05^{*}$ \\
\hline
\end{tabular}

ventilation and laryngoscopy were statistically significant $(p<0.05)$. No patient in the non-obese group had difficult ventilation or laryngoscopy (Table 5).

None of the anatomical or clinical variables assessed had significant correlation with difficult facemask ventilation in both groups. In obese patients, the polysomnography used to diagnose OSAS showed strong correlation with difficult laryngoscopy $(r=0.8)$. The other parameters had no good correlation with this outcome (Table 6). In obese patients undergoing polysomnography, weight, physical status, history of snoring, apnea during sleep, and mento-thyroid distance values showed good correlation with the diagnosis of OSAS (Table 7). 
Table 6 Correlation with Difficult Airway Access.

\begin{tabular}{lll}
\hline Predictor & $\begin{array}{l}\text { Difficult } \\
\text { ventilation }\end{array}$ & $\begin{array}{l}\text { Difficult } \\
\text { laryngoscopy }\end{array}$ \\
\hline BMI & $r=0.15$ & $r=0.12$ \\
Snoring & $r=0.17$ & $r=0.20$ \\
Neck circumference & $r=0.17$ & $r=0.19$ \\
Physical status & $r=0.27$ & $r=0.20$ \\
OSAS & $r=0.36$ & $r=0.80^{*}$
\end{tabular}

BMI: Body Mass Index; OSAS: Obstructive Sleep Apnea Syndrome.

Table 7 Correlation with Diagnosis of OSAS.

\begin{tabular}{ll}
\hline Predictor & Diagnosis of OSAS \\
\hline $\mathrm{N}$ & 9 \\
Weigh & $r=0.82$ \\
Snoring & $r=1.00$ \\
Physical status & $r=0.74$ \\
Nocturnal apnea & $r=0.80$ \\
Mento-thyroid distance & $r=0.73$ \\
\hline
\end{tabular}

\section{Discussion}

Difficult airway access and improper management are the main causes of complications in anesthetic practice ${ }^{8}$. The accurate preoperative diagnosis of difficult tracheal intubation may result in lower rates of anesthetic complications, particularly in obese patients.

It is believed that the airway access is more difficult in obese than in non-obese patients due to the anatomic changes resulting from excess weight ${ }^{8}$. In obese patients, there is a reversed relationship between weight and pharyngeal area due to fat deposition on cervical structures ${ }^{9}$. Thus, difficult intubation, sometimes defined as inadequate glottis exposure to direct laryngoscopy, is more prevalent in patients with high $\mathrm{BMI}^{8}$.

In the present study, consistent with literature reports, the incidence of snoring, $\mathrm{AH}$, and diabetes mellitus was higher in obese patients ${ }^{10}$. These findings were already expected, as obesity is an independent risk factor for arterial hypertension, insulin resistance, and nocturnal airway obstruction ${ }^{11}$.

Although obesity is a physical characteristic that is most associated with the diagnosis of obstructive sleep apnea ${ }^{9}$, the incidence of daytime sleepiness and apnea during sleep was similar in both groups. One possible explanation is that there are other factors associated with airway obstruction, such as septal deviation and tonsillar hypertrophy, whose incidence is similar between obese and non-obese individuals ${ }^{2,9}$.

The anatomical parameters of airway evaluation showed no difference between the two groups, which was similar to the study by Kim et al. ${ }^{4}$ The only exception was the value of neck circumference and Mallampati index, which were higher in the obese group. This may be explained by the fact that these patients had decreased pharyngeal area due to the excess of soft tissue in this region ${ }^{9}$.
Studies by Juvin et al. ${ }^{3}$ and Kim et al. ${ }^{4}$ showed higher incidence of difficult facemask ventilation in obese patients. However, its actual incidence in patients with a BMI $>30 \mathrm{~kg} / \mathrm{m}^{2}$ remains controversial because it is hard to define and given the variety of methods used ${ }^{8}$. In the present study, the proportion of obese patients with difficult facemask ventilation was $16.3 \%$, which is similar to previous studies ${ }^{2}$. Patients in the non-obese group had adequate facemask ventilation. The greater difficulty in obese patient's ventilation results from fat tissue deposition in the hypopharynx, uvula, tongue, and arytenoid folds, increasing the volume of these structures and reducing the free area for air passage.

According to current literature, the incidence of difficult intubation in obese and non-obese individuals is similar (about $10 \%)^{3}$. In our study, the incidence of difficult laryngoscopy in obese patients was $9.3 \%$. However, among non-obese patients there was no case of difficult intubation, compared with those reported in literature, which showed incidence around 10\% in this group ${ }^{3,4}$. This finding may be a consequence of the limited sampling size studied. The studies reporting similar incidences had at least 100 patients in each group ${ }^{3,4}$. The level of experience among the different physicians who accessed the airways in both groups could be another explanation for this finding. Nevertheless, there was no difference between groups regarding this variable.

According to studies by Kim et al. and Benumof, the incidence of difficult facemask ventilation in obese patients is superior to difficult laryngoscopy ${ }^{7,9}$. However, the explanation for this evidence remains controversial, as risk factors for both entities are quite similar. In the present study sample, the percentage of patients with difficult ventilation (16.7\%) was higher than that of patients with difficult laryngoscopy (9.3\%), which is consistent with the literature.

To date, no clinical predictor was directly correlated with difficult facemask ventilation in obese patients, similar to this study ${ }^{9}$. However, large neck circumference, modified Mallampati index (grade III or IV), and a previous diagnosis of OSAS with polysomnograply are among the predictors established as risk factors for difficult laryngoscopy ${ }^{3,8}$. In the present study, the only factor presenting good correlation with difficult laryngoscopy in obese patients was a previous diagnosis of OSAS with polysomnography. Variables such as gender, age, BMI, history of snoring, neck circumference and Mallampati index showed no correlation with CormackLehane classification III or IV in obese patients.

Evidence on literature indicates that obese patients with OSAS usually have a higher incidence of difficult laryngoscopy ${ }^{8,9}$. Anatomical measurements, such as reduced mouth opening, sternomental, and thyromental distances and greater neck circumference are highly related to both diagnosis of difficult airway access and OSAS. Another essential point is that the excess fat tissue in obese patients with OSAS may occur at the hypopharyngeal level, which makes the evaluation by Mallampati classification unreliable to predict difficult intubation. The finding of a good correlation between the preoperative diagnosis of OSAS and difficult airway access in obese patients comes as no surprise ${ }^{9}$. Thus, assessing the presence of clinical predictors of OSAS is a valuable tool to aid in the prediction of difficult airway management in obese patients. 
One limitation of our study was the poor availability of polysomnography in the preoperative period. Among obese patients, nine $(20.9 \%)$ underwent polysomnography, while, among non-obese patients, only one $(2.2 \%)$ underwent a sleep study. This detail hampered the correlation between the evaluated clinical predictors and the diagnosis of obstructive sleep apnea. The American Thoracic Society and the American Academy of Sleep Medicine recommend supervised polysomnography over two nights in the sleep laboratory. For a highly prevalent condition, this approach results in inevitable differences between service demand and sleep laboratories current capacity. Despite the limitation, the weight, physical status, history of snoring, apnea during sleep, and mento-thyroid distance values showed good correlation with the polysomnographic diagnosis of OSAS in the obese group.

Another limitation of this study was the sample size. The number of patients analyzed was slightly higher than the minimum required, so that the findings were not explained by chance. However, the sample was similar to that of other studies with the same focus ${ }^{8}$.

The assessment of some important predictors of obstructive sleep apnea may be considered as a quality in this study, as it has been poorly studied so far. Recent works, such as the one by Ramachandran et al., designed clinical questionnaires for diagnosis of OSAS in the preoperative period ${ }^{12}$. However, the authors did not evaluate predictors, such as sleepiness, daytime fatigue, or history of apnea during sleep.

Further studies with larger samples should be conducted to determine the clinical predictors that can assist in the diagnosis of difficult laryngoscopy, as a way to decrease the incidence of complications related to inadequate airway management in obese patients.

The clinical and polysomnographic diagnosis of OSA proved useful in the preoperative diagnosis of difficult laryngoscopy. Obese patients are more prone to difficult facemask ventilation and difficult laryngoscopy than nonobese individuals.

\section{References}

1. Mancini MC - Diagnóstico e classificação da obesidade. Em: Garrido Júnior $A B$ - Cirurgia da obesidade. São Paulo: Atheneu, 2002;1-7.

2. Simoni RF - Anestesia para cirurgia bariátrica. Em: Cangiani LM, Posso IP, Potério GMB, Nogueira CS - Tratado de anestesiologia. $6^{a}$ ed. São Paulo: Atheneu, 2006; 1595-613.

3. Juvin $\mathrm{P}$, Lavaut $\mathrm{E}$, Dupont $\mathrm{H}$, et al. - Difficult tracheal intubation is more common in obese than in lean patients. Anesth Analg. 2003; $97: 595-600$.

4. Kim WH, Ahn HJ, Lee CJ, et al. - Neck circumference to thyromental distance ratio: a new predictor of difficult intubation in obese patients. Br J Anaesthesia. 2011;106:743748.

5. Martins AB, Tufik S, Moura SMGPT - Síndrome da apneiahipopneia obstrutiva do sono. Fisiopatologia. J Bras Pneumol. 2007;33(1):93-100.

6. Braga AFA, Silva ACM, Cremonesi E - Obesidade mórbida: considerações clínicas e anestésicas. Rev Bras Anestesiol. 1999;49:201-12.
7. Ramachandran SK, Josephs LA - A meta-analysis of clinical screening tests for obstructive sleep apnea. Anesthesiology. 2009;110:928-39.

8. Brodsky JB, Lemmens HJM, Brock-Utne JG, Vierra M, Saidman LJ - Morbid obesity and tracheal intubation. Anesth Analg. 2002;94:732-736.

9. Benumof $\mathrm{JL}$ - Obstructive sleep apnea in the adult obese patient: implications for airway management. J Clin Anesthesia. 2001;13:144-156.

10. Punjabi NM - The epidemiology of adult obstructive sleep apnea. Am Thorac Soc. 2008;5:136-143.

11. Neligan PJ, Porter S, Max B, Malhotra G, Greenblatt EP, Ochroch EA - Obstructive sleep apnea is not a risk factor for difficult intubation in morbidly obese patients. Anesth Analg. 2009;109:1182-6.

12. Ramachandran SK, Kheterpal S, Consens F, Shanks A, Doherty TM, Morris M, Tremper KK - Derivation and validation of a simple perioperative sleep apnea prediction score. Anesth Analg. 2010;110:1007-15.

13. Mulgrew AT, Fox N, Ayas NT, Ryan CF - Diagnosis and initial management of obstructive sleep apnea without polysomnography. Ann Intern Med. 2007;146:157-166.

14. Herer B, Roche N, Carton M, Roig C, Poujol V, Huchon G - Value of clinical, functional, and oximetric data for the prediction of obstructive sleep apnea in obese patients. Chest. 1999;116(6):15371544.

15. Ahmad S, Nagle A, McCarthy RJ, Fitzgerald PC, Sullivan JT, Prystowsky $\mathrm{J}$ - Postoperative hypoxemia in morbidly obese patients with and without obstructive sleep apnea undergoing laparoscopic bariatric surgery. Anesth Analg. 2008;107:13843.

16. Blake DW, Chia PH, Donnan G, Williams DL - Preoperative assessment for obstructive sleep apnoea and the prediction of postoperative respiratory obstruction and hypoxaemia. Anaesth Intens Care. 2008;36:379-84.

17. Gross JB, Bachenberg KL, Benumof JL, et al. - Practice guidelines for the perioperative management of patients with obstructive sleep apnea: a report by the American Society of Anesthesiologists Task Force on Perioperative Management of patients with obstructive sleep apnea. Anesthesiology. 2006;104:1081-93.

18. Kirby SD, Engl P, Danter W, et al. - Neural network prediction of obstructive sleep apnea from clinical criteria. Chest. 1999;116:409-15.

19. Kushida CA, Efron B, Guilleminault C - A predictive morphometric model for the obstructive sleep apnea syndrome. AnnIntern Med. 1997;127:581-7.

20. Chung F, Yegneswaran B, Liao P, et al. - Stop questionnaire: a tool to screen patients for obstructive sleep apnea. Anesthesiology; 2008;108:812-21.

21. Chung $F$, Yegneswaran B, Liao P, et al. - Validation of the Berlin questionnaire and American Society of Anesthesiologists checklist as screening tools for obstructive sleep apnea in surgical patients. Anesthesiology. 2008;108:822-30.

22. Liistro G, Rombaux P, Belge C, Dury M, Aubert G, Rodenstein DO - High Mallampati score and nasal obstruction are associated risk factors for obstructive sleep apnoea. Eur Respir J. 2003;21:24852.

23. Toshiya S, Wajima Z, Inoue T, Sakamoto A - Predicting difficult intubation in apparently normal patients. Anesthesiology. 2005;103:429-437. 